Afr. J. Trad. CAM (2005) 2 (3): 337 - 344

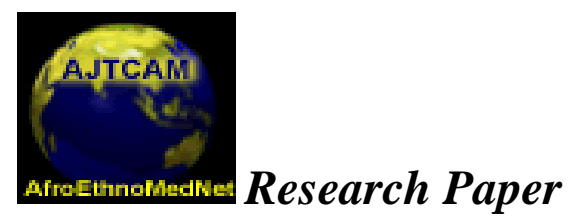

Afr. J. Traditional, Complementary and Alternative Medicines www.africanethnomedicines.net

ISSN 0189-6016@2005

\title{
A SURVEY OF TREATMENT PRACTICES FOR FEBRILE ILLNESSES AMONG TRADITIONAL HEALERS IN THE NIGERIAN MIDDLE BELT ZONE
}

\author{
Oladunni Osowole $^{\mathrm{a}}$, Edith Ajaiyeoba ${ }^{\mathrm{b}^{*}}$, Olayinka Bolajic, Dora Akinboye ${ }^{\mathrm{d}}$, \\ Olufumilayo Fawole ${ }^{\mathrm{e}}$, Catherine ${ }^{\mathrm{f}}$, Grace Gbotosho ${ }^{\mathrm{f}}$, Omonike Ogbole ${ }^{\mathrm{g}}$ Joseph \\ Ashidi $^{\mathrm{b}}$, Oyindamola Abiodun ${ }^{\mathrm{g}}$, Catherine Falade ${ }^{\mathrm{d}}$, Woquan Sama ${ }^{\mathrm{b}}$, Oladimeji \\ Oladepo $^{\mathrm{a}}$, Oludele Itiola ${ }^{\mathrm{h}}$, Ayoade Oduola ${ }^{\mathrm{b}}$
}

${ }^{\mathrm{a}}$ Department of Health Promotion and Education, Faculty of Public Health, College of Medicine, University of Ibadan, Ibadan, Nigeria, ${ }^{\mathbf{b}}$ Department of Pharmacognosy, Faculty of Pharmacy, University of Ibadan, Ibadan, Nigeria, 'Institute of Advanced Medical Research and Training, College of Medicine University of Ibadan, Ibadan, Nigeria, ${ }^{\mathbf{d}}$ Department of Zoology, Faculty of Science, University of Ibadan, Ibadan, Nigeria, ${ }^{\mathrm{e}}$ Department of Epidemiology, Biostatistics and Environmental Health, Faculty of Public Health, College of Medicine, University of Ibadan, Ibadan, Nigeria, f Department of Pharmacology, College of Medicine, University of Ibadan, Ibadan, Nigeria, ${ }^{\mathbf{g}}$ Department of Pharmacognosy, Faculty of Pharmacy, Olabisi Onabanjo University Sagamu, Nigeria, ${ }^{\mathbf{h}}$ Department of Pharmacology, Ladoke Akintola University, Osogbo, Nigeria, 'Department of Pharmaceutics and Industrial Pharmacy, Faculty of Pharmacy, University of Ibadan, Ibadan, Nigeria.

Email: e.ajaiyeoba@mail.ui.edu.ng edajaiye@yahoo.com

Telephone: 234 - 8023222796; $234-2-8101100$ - 4. Fax: $234-2$ - 2411768;

$$
234-2-8103043 \text {. }
$$

\section{Abstract}

This survey was conducted to investigate the pattern of treatment practices for febrile illnesses among one hundred and eighty five traditional healers from the Nigerian Middle belt zone ethnomedicine. Data collection was through use of the semi structure questionnaire administered by trained interviewers recruited from the study sites - Gboko and Katsina Ala Local Government Areas. A total of 176 (95.1\%) reportedly diagnosed through the presenting complaints and symptoms and 3 (1.6\%) made diagnoses through divination. All the respondents indicated their referral practices, with 100 (54.1\%) of the respondents reported that they had once referred clients. Respondents listed 164 plants used in the preparation of the various treatment modalities. Institution of treatment follows this diagnostic practice. Treatment of different febrile illnesses involve the use of 


\section{Afr. J. Trad. CAM (2005) 2 (3): 337 - 344}

liquid herbs, powdered herbs, medicinal scarifications, incantations and sacrifices which suggests the confidence this group has in the efficacy of their herbs for treating febrile illnesses. An appreciable level of referral $54.1 \%$ practice was also found among the traditional healers. The findings of this study strengthen the need to recognize the traditional health practitioners in the treatment of health problems especially febrile illnesses, and to establish quality control mechanism in partnership with them to improve their treatment practices.

Key words: Fever, traditional, treatment practices, Nigeria, middle belt

\section{Introduction}

Malaria is a major cause of morbidity and mortality in most parts of the developing countries (Ramakrishna et al., 1989) and remains one of the major infectious diseases in the world with about 2.8 billion (60\%) of the world population living with malaria in endemic areas. Ninety percent of all malaria cases in the world occur in sub-Saharan Africa, where the disease has become the second leading endemic health problem (WHO, 2000). Thus the poorest countries bear the greatest burden of mortality and morbidity from this disease. Malaria accounts for $30-35 \%$ of persons seeking health care at rural dispensaries (Kengeya - Kayondo et al., 1994) and 20 - 25\% of all admissions in African health services (Brinkman and Brinkman, 1991). In Nigeria, malaria is a major contributory factor and a leading cause of mortality among all age groups. It accounts for more than $25-30 \%$ mortality rate among children less than five years of age.

Furthermore, quite a number of pregnant women are affected annually as these groups of people are the most vulnerable to the disease. Despite the magnitude of the disease in developing countries; modern medicines are often not available and where available the cost makes it beyond the reach of the poor people in most of the rural areas. The rapid spread of parasite resistance to drugs has made case management and chemoprophylaxis more difficult and less successful thus making the need to search for more potent, affordable and cost effective alternative very urgent. This has led to the increased popularity in the use of herbs in case management of malaria. It has been documented that traditional seeking behaviour for malaria is related to cultural beliefs about the causes and cure of malaria (Bledsoe and Goubaud, 1985). The World Health Organisation estimated that $80 \%$ of the world's population use botanical medicines for their primary health care needs, malaria treatment inclusive (Farnsworth et al., 1985). In Africa, traditional health care providers are culturally relevant and their clientele increasing due to accessibility, reduced cost and flexibility in mode of payment, timing benefit and effective communication in the various local dialects. However, the efficacy of the various herbal treatment given by the traditional health care provider depend to a large extent on the knowledge of the various aspects of the disease, diagnostic methods and treatment options. The South African Medical Journal in 1994 reported that 80\% of patients were consulting a traditional healer either exclusively or before or after attending a clinic or hospital. However, this widely patronized body of health care providers remains 
Afr. J. Trad. CAM (2005) 2 (3): 337 - 344

unrecognized and their treatment practices remain a mystery putting both health care providers and their clients at a disadvantaged position.

This survey set out to examine how traditional healers in the area under study interpret the symptoms and illnesses, which are presented by caregivers. Also to assess diagnostic practices, types of treatment resulting from these interactions and explore the socio-cultural basis for treatment decisions with the aim of enhancing traditional healers treatment practices for febrile illnesses especially malaria.

\section{Methodology}

The study was an ethnobotanical survey carried out in Middle belt geographical zone of Nigeria. Two sites - an urban Local Government Area (LGA), which is Gboko LGA, and a contiguous rural LGA, Katsina Ala LGA - were randomly selected. Advocacy visits were made to the traditional healers in the two sites to explain the rationale for the study, obtain their approval and to enlist the support of the association and key personalities in the communities. Visits were made to the primary health care centres in both sites to inform the health workers of the study while courtesy visits were also made to traditional and community leaders as well as to opinion leaders. Interviewers were recruited locally from the two sites and were trained for a period of one week on interview techniques and documentation of responses. The instrument developed was pre-tested in Offa - Igbo, Lagelu LGA of Oyo State an urban LGA and Apomu, Isokan LGA of Osun State, a rural LGA. Pre-testing the instrument as part of the methodology is to ascertain its effectiveness. After the pretest, amendments were made and the actual data collection was done. An approval for the study was obtained from the traditional healers' association and an informed consent was obtained from each respondent before commencement of the interview. The respondents were randomly selected from the community. The responses were manually coded using the thematic areas and then analyzed statistically the using EPI INFO version 6 .

\section{Results}

\section{Sociodemographic Characteristics}

One hundred and eighty five traditional healers were interviewed. These consisted of herbalists, herb sellers and diviners (Table 1). Majority of the respondents 122 (67.8\%) were herbalists that took the art as a profession. Information on acquisition of skill showed that half of the respondents (50.0\%) inherited it from their parents, 83 (46.6\%) passed through a period of tutelage while 6 (3.4\%) indicated that the skill was a supernatural gift through a dream or vision. Years of experience recorded showed that respondents had been in practice between one to 62 years.

\section{Health Problems Presenting to the Traditional Healers}

Both adults and children consult respondents from this study sites. Health problems brought to respondents which were peculiar to children as cited by respondents in order of 
Afr. J. Trad. CAM (2005) 2 (3): 337 - 344

Table 1: Socio - demographic characteristics of respondents

\begin{tabular}{|l|l|}
\hline Type of respondents & Responses No. (\%) \\
\hline Herbalist & $122(67.8)$ \\
\hline Community leader & $28(15.6)$ \\
\hline Herb sellers & $24(13.3)$ \\
\hline Diviners & $6(3.3)$ \\
\hline Skill acquisition & \\
\hline Inheritance & $89(50.0)$ \\
\hline Training & $83(46.6)$ \\
\hline Supernatural Gift & $6(3.4)$ \\
\hline
\end{tabular}

magnitude, as shown in Table 2, included fever (24.3\%), headache (12.0\%), weakness (11.5\%), cough (9.8\%) and convulsion (9.4\%). For adults, presented health problems in order of magnitude were fever (17.8\%), weakness (16.5\%), body pain (15.4\%), headache (15.5\%), loss of appetite (11.5\%) and cough (7.6\%). The Table revealed that fevers, headache and weakness were the most common symptoms among both children and adults while children experience convulsion more. Specifically, respondents saw different types of fevers. The list of the types of fever in order of magnitude is listed in Table 3.

\section{Treatment Practices among Respondents}

Respondents were asked on their diagnostic techniques. Results showed that 176 (95.1\%) diagnose through the presenting complaints and symptoms and 3(1.6\%) diagnose through divination. Institution of treatment followed the diagnostic practice.

Respondents cited different modalities as to the treatment of febrile illnesses and convulsion. The modalities cited for fever as shown in Figure 1 were administration of liquid herbs, powdered herbs, special fluids, incantation, scarification and sacrifices. For convulsion modalities included liquid herbs, powdered herbs, scarifications, special fluids, incantation and sacrifices. From the results, liquid preparation was the most common presentation of herbal remedy. Powdered preparation, sacrifices and scarification were used more for the treatment of convulsion.

Respondents listed 164 plants used in the preparation of the various treatment modalities. Of these 164, 12 plants shown in Table 4 were identified to be commonly used for the treatment of illnesses brought to the healers.

All the respondents indicated their referral practices. Only $100(54.1 \%)$ of the respondents reported that they had referred clients before. Reasons for referral were nonimprovement in client's illness 17 (41.1\%), inability to diagnose the type of illness brought $16(17.6 \%)$ and illness not being in their specialty area $8(10.5 \%)$. Of the cases that were referred, $41.0 \%$ were referred to the hospital, $2.0 \%$ to senior colleagues while the remaining $57.0 \%$ did not specify place of referral. The 85 (45.1\%) that did not refer had no reason for doing so as they were able to handle all cases brought to them. 
Afr. J. Trad. CAM (2005) 2 (3): 337 - 344

Respondents proffered suggestions for improving their treatment practices. These were; improving storage facility for their herbs, standardization of dosages and conservation of medicinal plants and forest reserve.

\section{Discussion}

The study showed that most of the respondents acquired their skill from their parents. This is not surprising as traditional health knowledge and skill is usually passed down from one generation to another. This is in line with the findings of Sofowora (1993) who reported that Orunmila's younger brother gained the traditional healing knowledge through assisting his elder brother to compound drugs. Also the finding that some of the respondents received their healing skill through trance was corroborated by Makhubu (1978).

Table 2: Presenting health problems seen by respondents among children and adults

\begin{tabular}{|l|l|l|}
\hline \multirow{2}{*}{ Health Problems } & \multicolumn{2}{|c|}{ Responses } \\
\cline { 2 - 3 } & $\begin{array}{l}\text { Children } \\
\text { No. (\%) }\end{array}$ & $\begin{array}{l}\text { Adults } \\
\text { No. (\%) }\end{array}$ \\
\hline Fever & $156(24.3)$ & $124(17.8)$ \\
\hline Headache & $83(12.0)$ & $108(15.5)$ \\
\hline Weakness & $74(11.5)$ & $115(16.5)$ \\
\hline Cough & $63(9.8)$ & $53(7.6)$ \\
\hline Convulsion & $60(9.4)$ & $17(2.4)$ \\
\hline Diarrhoea & $59(9.2)$ & $48(6.9)$ \\
\hline Body pain & $57(8.9)$ & $107(15.4)$ \\
\hline Loss of appetite & $54(8.4)$ & $80(11.5)$ \\
\hline Red eyes & $35(5.5)$ & $44(6.3)$ \\
\hline
\end{tabular}

Table 3: Types of fever treated by respondents

\begin{tabular}{|l|l|}
\hline \multicolumn{1}{|c|}{ Types of fever } & \multicolumn{1}{c|}{ Responses } \\
\hline Yellow Fever & $138(36.0)$ \\
\hline Typhoid Fever & $90(23.5)$ \\
\hline Malaria Fever & $68(17.8)$ \\
\hline High Fever & $67(17.5)$ \\
\hline White Fever & $14(3.7)$ \\
\hline Ordinary Fever & $6(1.6)$ \\
\hline
\end{tabular}

Diagnosing practices of the respondents revealed that they diagnose through physical examination, patients' complaints and divination. It would be observed that the 
Afr. J. Trad. CAM (2005) 2 (3): 337 - 344

first two diagnostic methods correspond with those of the orthodox health practitioners. The use of divination (the consultation of the oracle about or on behalf of a client) in diagnosis corroborates the findings of Osunwole (1992) who documented it as a major way of diagnosis among traditional healers.

The study found that respondents treat febrile illnesses using diverse methods. Treatment modalities mentioned were the use of Liquid herbs, powdered herbs, medicinal scarifications, incantations and sacrifices. These modalities brought to the fore the traditional healers' perception of the different illnesses and perceived threats to life as liquid and powdered herbs are usually used in treating febrile illnesses considered minor while scarification and sacrifices are used for perceived life threatening cases. The list of

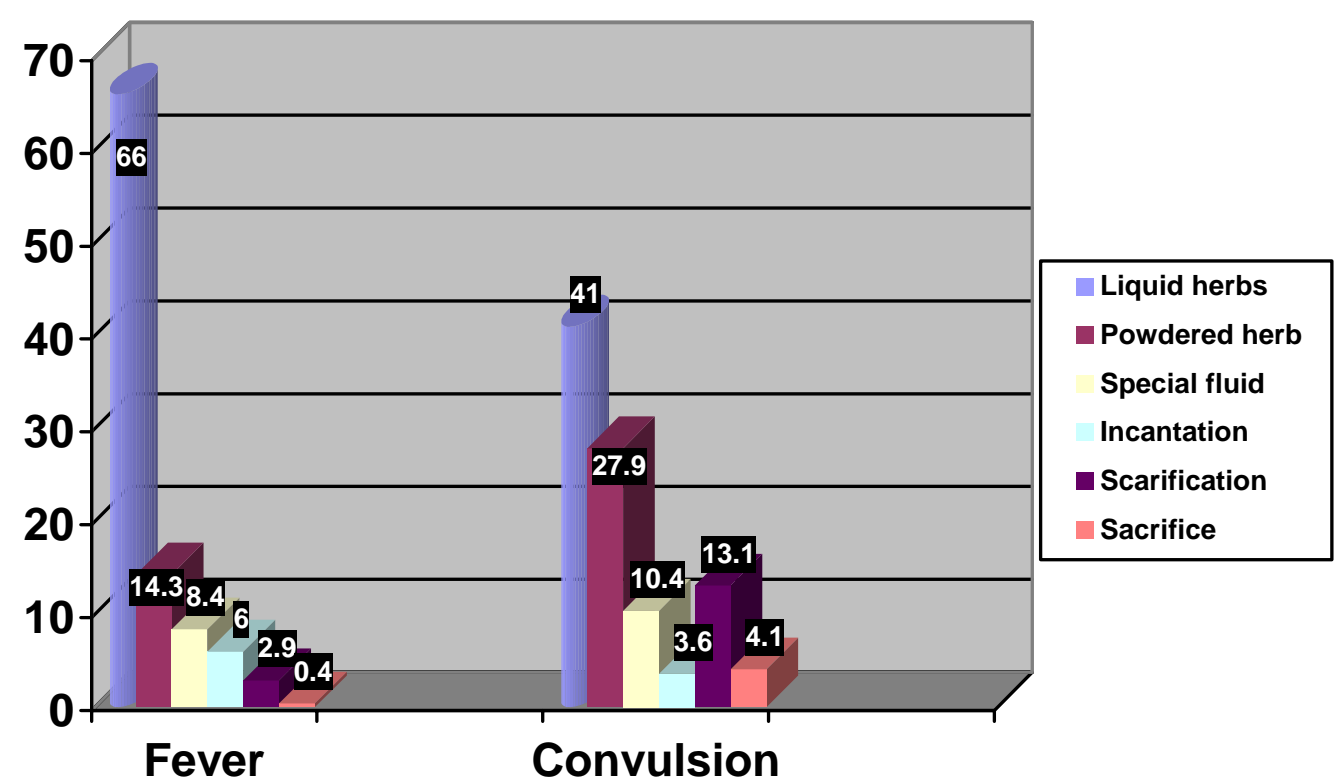

Figure 1: Treatment modalities for fevers and convulsion

herbs used by this group of traditional healers is not at variance with earlier studies by Ramakrishna et al. (1989) and Brieger et al. (1986). Of importance is the finding that the respondents refer clients to other levels of care. The reasons given for referral included non improvement in the case after treatment, inability to diagnose illness and area of specialty different. This is a practice that should be strengthened for proper management of febrile illnesses through the establishment of a strong referral network among this group of people and between this group and orthodox health professionals. 
Afr. J. Trad. CAM (2005) 2 (3): 337 - 344

Table 4: List of plants commonly used for treatment of illnesses by healers

\begin{tabular}{|l|l|}
\hline Local Names & \multicolumn{1}{|c|}{ Botanical Names } \\
\hline Dongoyaro & Azadirachta indica (Meliaceae) \\
\hline Akinde & Ficus thonnigii \\
\hline Isoho & Erythrina senegalensis \\
\hline Ikpine & Bridelia micrantha (Euphorbiaceae) \\
\hline Kuhwa & Cassia alata (Fabaceae) \\
\hline Kuhwa-indya & Cassia occidentalis (Fabaceae) \\
\hline Yankpade & Pilostigma thonningii (Fabaceae) \\
\hline Gydam & Jatropha curcas (Euphorbiaceae) \\
\hline Kungraku utane & Ocimum basilicum \\
\hline Tsada & Haematostaphis barteria \\
\hline Ahur & Annona senegalensis (Annonaceae) \\
\hline Ikuraukase & Nauclea latifolia (Rubiaceae) \\
\hline
\end{tabular}

\section{Conclusion}

The study has shown that a great majority of the indigenous communities of Gboko and Kastina-Ala patronize traditional medicine practitioners for treatment of febrile illnesses. In addition the study has revealed that that in the study areas, the traditional healers have improved their practices by diagnosing the illnesses based on complaints and observed symptoms. The practice of referral system is also used by the traditional healers. These are main ingredients of orthodox medical practice that were hitherto thought to be absent in traditional medical practice. This goes further to prove that the integration of traditional medicine into the health care delivery system in Nigeria is imperative.

\section{Acknowledgements}

This study received financial support from WHO/TDR/MIM Africa research capability Strengthening Grant ID 980046. We are grateful to the respondents, the Traditional Healers’ Associations in Gboko and Katsina-Ala Local Government Areas of Benue State.

\section{References}

1. Bledsoe C. H. and Goubaud, M. F. (1985). The reinterpretation of western pharmaceuticals among the Mende of Sierra Leone. Soc. Sci. \& Med. 21(3): 275.

2. Brieger, W. R., Ramakrishna, J. W. R. and Adeniyi J. D. (1986) Self treatment in rural Nigeria. Hygiene 5(2): $41-46$. 
Afr. J. Trad. CAM (2005) 2 (3): 337 - 344

3. Brinkman U. and Brinkman A. (1991). Malaria and Health in Africa: the present situation and epidemiological trends. Trop. Med. \& Parasitol. 42: 204 - 213.

4. Farnsworth, N. R., Akerele, O., Bingel, A.S., Soejarto, D. D. and Guo Z. (1985) Medicinal Plants in Therapy. Bulletin the WHO 63: 965 - 81.

5. Kengeya - Kayondo, J (1993) Rural women's recognition of malaria: their treatment seeking behaviour and how the latter is influenced by perception of cause. WHO/TDR/SER Final Report. 520/18/SER/73.

6. Makhubu L. P. (1978). The Traditional Healer. Umbabane: University of Botswana and Swaziland.

7. Osunwole S. A. (1992). Healing by Incantations: the Yoruba Experience. Afri. Notes 16: $71-78$.

8. Ramakrishna, J.W.R., Brieger, W. R. and Adeniyi J. D. (1989). Treatment of malaria and febrile convulsions. An educational diagnosis of Yoruba beliefs. Int. Quartr. Commun. Health Educ. 9: 305 - 319.

9. Sofowora, A. (1993). Medicinal Plants and Traditional Medicine in Africa. Spectrum books limited. Book. pp.12

10. World Health Organisation (2000). General Guidelines for Methodologies on Research and Evaluation in Traditional Medicine. Newsletter vol. 15 no 2. 